\title{
Design and Implementation of the Evaluation System of art Display Design Based on Ergonomics
}

\author{
Xin Yu, Ling Chen \\ \{yuxin@163.com\}
}

College of art and design wuchang shouyi university, wuhan 430064, China

\begin{abstract}
Paper first focus on interactive media interface elements of the visual language, content structure in detail, and then analyzes the relationship between the interface of man-machine engineering and information architecture design, based on key elements of man-machine engineering principle and interface design method and content. Then put forward to improve the interactive media interface design process and design method based on human computer engineering, and research the key technology of interactive media courseware production. Using the method of man-machine engineering, the design scheme of the application of text, interface color, interface layout and multimedia material is studied. In the interactive media courseware design, because lingo language occupies the proportion of larger, so focus on the basic application technology of LINGO language Dircetor and video and sound production technology, product below the multimedia product design art, interactive media courseware of laid the foundation for the realization of. Finally according to the technology in interactive media production characteristics and Dircetor media interactive interface design, from the technology and the art of perspective and practicality, the system of interactive media works for the design, from interactive works of creative design and analysis, the frame structure design, view design, interface design elements such as were studied in detail. And to support interactive technology of the interactive media courseware application works Dircetor analysis and research, focus on show the works in the interactive effect of design and production process, theoretical methods described in the paper is verified, thus demonstrating that based on ergonomics of interactive media interface design method is correct and guidance, and ultimately the formation of the multimedia product design art, interactive media courseware works.
\end{abstract}

Keywords: Ergonomics; interactive media; interface; display design

\section{Introduction}

Interactive media as information is an important means to obtain a direct impact on people's daily life, the current environment, we are faced with two kind of situations, on the one hand, information has become influence human life and economic development, social progress, the important aspect. On the other hand, information overload also brings a negative impact on human life and social progress. Then we are faced with the contradiction between the dispersion of information, the disorder of the information and the selectivity of the information. How to exchange information effectively [1], how to enable people to effectively, quickly and accurately access to information is the problem we need to solve. Design is no 
longer limited to piles of combination of physical design objects and appearance decoration, but more and more emphasis on the user experience of the product and emotional design, product brings the "emotional gratification" rather than the function value ", emphasizing product system organizational structure, intelligent, interaction and experience of. The purpose of the design of the information age is to make the information in an orderly, accurate and effective way to use, design activities focused on the grasp and application of human engineering and information analysis and processing. Design process is in fact the surface are the various contradictions in the conflict of coordinated process, all of the success of the design is to seek balance and harmony between the artistic beauty, reliability, safety, easy to use, cost and function. We should not only in the pursuit of a certain effect to design, the designer as a "makeup", we can not alone a works to a design good and bad results, any design left the circumstances in which it was impossible. Due to the influence of traditional ideas, for a long time, ergonomics has not been paying attention to interactive media product design and development staff that this is purely to please users of lower activity, without any practical value. The only criterion for evaluating the quality of a design product is to see if it has a powerful function and can help users to complete the tasks they require. In recent years, with the rapid development of computer hardware technology, technical performance of the computer running speed, storage capacity and reliability have improved significantly, computer hardware, the cost of production is greatly decreased, personal computer becomes more and more popular. A new generation of computer users, the interface design of operation and operation comfortable aspects of interactive media design put forward higher requirements, in addition to want to use the design has a strong function, expected product design can they provide a pleasant, relaxed, feel good operating environment. This shows that the application of ergonomics has become a big problem, friendly man-machine interface design has become an important part of interactive media design.

\section{Elements and Contents of Human Computer Engineering in Interactive Media Interface}

A wide variety of media names have become a worldwide hot term. "Multimedia", "digital media" "interactive media", "new media" and so on, regardless of is professionals and non professionals, whether deep pass the connotation or from the gossip just heard, it has openly become indicators of life time. It is necessary to make clear the distinction and connection between them. Digital media is in the development of contemporary computer technology a and art related information revolution achievements, with the popularity of the development of digital technology and computer, the concept of digital media and went on to become the people to explore the topic, especially the mankind has entered the information age today, the birth of a new [2], three-dimensional full range of information highway. It also reflects the necessity of application of modern technology development, it is indeed an era of the newborn. Now the digital media is mainly refers to the Internet, people tend to the network media form is called the digital media, the interaction of freedom. But as a constant renewal and development of new technology, his definition is also constantly enrich and update. 

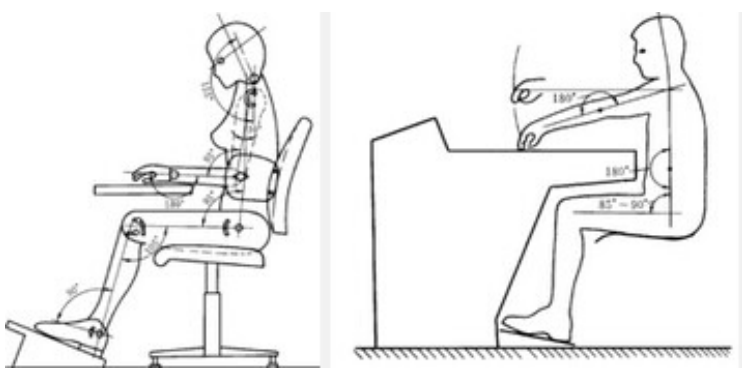

Fig. 1. Man-machine engineering example

\subsection{Research on the Content of Design Based on Ergonomics}

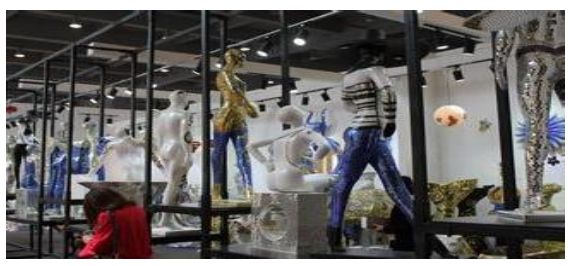

Fig. 2. Examples of art display design

User experience of interactive media interface to cope on ever use of functional operation of skilled, function of the unused can combined with experience and independent thinking and use, so that users we call user experience or expert users. They are often able to find the meaning of the interface of the deep information, with a high level of information classification and comprehensive ability. In the face of the experience of the user's interactive media interface style design, should try to meet the needs of users, to give users a free space to play. The ultimate goal of the design is to design for the person, not the product, this is the first principle of design. Therefore, in the design must fully consider the human factor. Ergonomics is the "human factor" as an important condition to consider. Ergonomics is ergonomics a important research direction, to the interactive media interface design fully consider the "human factor" provides the structure of the human body scale, human physiological and psychological scale data, the reliable data can effectively use of interactive media interface design to [3].

\subsection{Content of Design Language Based on Ergonomics}

In the art design of interactive media interface, color as an important visual language is also an important means to obtain information and sensory experience. The tone of a work and the use of color determine the tone of the whole work. Interface color gives people the feeling should be and work content is consistent, because color is the user interface in the process of guiding the user behavior and influence the user psychology is one of the important factors to deepen the theme, to express feelings, to heighten the atmosphere plays a unique role. Words to express the biggest feature is the accuracy of the ideographic, but the writing is not only confined to convey information, and is a noble form of artistic expression, through the combination of the words can give a person with rich imagination. Text as an important design 
language is the core of any visual interface, but also designed to convey the most direct way. The use of carefully processed text materials, can produce a very good interface, and do not need any graphics, leading people to the new perspective of aesthetic fashion. Therefore, to control the text, the design will be successful in half, and even all [4].

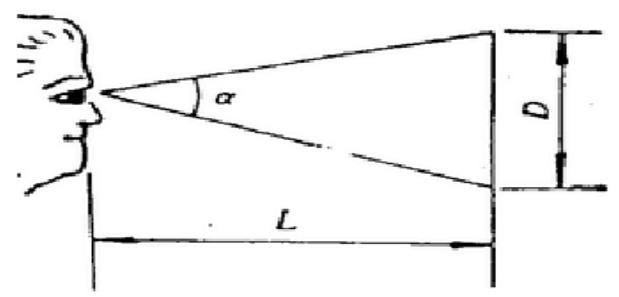

Fig. 3. Eye design for Art Exhibition

\section{Design and Implementation of the System}

Different colors can give people different feelings. Therefore, in the design of interactive media courseware interface should pay attention to the use of different colors in different content, not in order to beautiful and optional. A courseware interface should have a main color, but also to have a whole layout style, so that can maintain the user's emotional stability, is very necessary. Such as excessive use of color, will affect the concentration of the user's attention, learning mood, it is easy for users to generate a sense of fatigue. Therefore, the color appear in an interface should try to control in three to four, avoid the use of color too much, keep color before and after the use of consistency and the overall style, it gives people a specification, stable and the simplicity and clarity of psychological feeling and visual effects. In the color of the interface design should pay attention to the background color and text color not to use close to the color, which is not conducive to the user to identify the text, and produce visual fatigue, reduce efficiency. The contrast between the color and the color of the human eye has a certain relationship, when people from far away from the place to distinguish a variety of colors, then the color is easy to distinguish the order of red, green, yellow, white. If the two color matching, easy to distinguish several combinations are: yellow background, black words on black bottom mispronounced character, white lettering on a blue background, white background and black characters, such as, in the interface design color selection is very important.

In the design of interactive media courseware interface, the screen layout is reasonable, can directly reflect the quality of courseware. In script design, to screen is divided into several functional areas, various types of information put in a relatively fixed position, try to maintain a consistent, to avoid users looking for functional areas of spending too much time and energy on, to focus energy affects the teaching content to watch. In order to realize the man-machine engineering principle of interactive media courseware making, in the interactive interface design stage to use director lingo language code preparation, here for the production of the text, video playback sound technology and play several key technologies are studied. Director software is not just a tool for making animations or activities. Can also produce a complete application, Web short program and software tools, production games, teaching software and 
commercial software, etc.. Director is powerful, the key lies in its programming language Lingo. Multi line Lingo code can be composed of the program, in Director, the program is composed of multiple lines of Lingo code is in the form of play (Script) actors in the form of an actor in the table. They can be divided into four different types of script actors: the film actor (Script Movie), the actor (Script Behavior), the father of the script (Script Parent), actor table play (Script Cast). Lingo code language is the key to the production of Director [5].

\section{Conclusion}

The application of ergonomics in the design of interactive media as the basis of investigation and study, to the theory of ergonomics based, with experience of interactive digital media as the breakthrough point, the application of ergonomics in the design of interactive media interface of, and combining with the author's design examples verify the theoretical methods, enriches the category of ergonomics. Interactive media interface is an important branch of man-machine interface, study the interactive media interface for system design has important significance and interactive media interface design is ergonomics, industrial design and related media interactive development theory is a cross discipline, is a multidisciplinary integration. In this paper, through the interactive media design and ergonomics of the cross study, in the analysis and design of the author's practice to draw a more perfect design method. But due to its energy is limited, time constraints and realistic conditions of the relationship, this paper in the research process inevitably exist some imperfect places, some details are still to be refined. Therefore, in the future on the subject still need to do further research.

\section{References}

[1] Wu Yongchun, Huang Yuyu. Discussion and practice of software interface design technology. Journal of engineering graphics. No. 06. (2013)

[2] Qin group. Packaging engineering design of. multimedia console based on ergonomics. No. 11. (2012)

[3] Yu Yue, Nie Guiping. The improved design of pot handle. Journal of Donghua University (Natural Science Edition). No. 03. (2014)

[4] Gallen, Chang De Lu, in the Mingjiu, Huang ting. Based on ergonomics of city bus design method. Mechanical design and manufacturing. No. 06. (2013)

[5] Xu Meng, Sun Shouqian, Pan Yunhe. A virtual human body model for working space design. China mechanical engineering. No.08(2011) 